\title{
Reformas económicas en Chile, 1973-2017. Ricardo Ffrench-Davis.
}

\author{
(Penguin Random House Grupo Editorial, \\ Santiago, Chile, 2018). \\ Viviana Arévalo Molina ${ }^{1}$
}

En este trabajo, el economista chileno Ricardo Ffrench-Davis indaga acerca de los procesos económicos ocurridos en un periodo determinado -no azarosamente- en Chile, mediante un enfoque comparativo basado en series estadísticas, cifras y aspectos económicos.

El texto cubre en detalle lo que se consideró como determinante de las reformas y las políticas económicas de los 16 años y medio de dictadura, 20 años de la Concertación de Partidos por la Democracia, el gobierno de derecha que le siguió y el gobierno liderado por la Nueva Mayoría. Tal envergadura temporal tiene su justificación en el fenómeno que se quiere evidenciar: la aplicación de un modelo "neoliberal" en su forma más extrema; sin embargo, el propio autor señala que dicha aseveración debe alejarse de los mitos, generalizaciones, modas y extremismos, puesto que en el transcurso de más de cuarenta años han existido diferentes periodos con diversas reformas que ponen en práctica múltiples énfasis, derivando resultados económicos y sociales variados. Por tanto, la existencia de un único modelo económico instaurado, con una visión rígida y cimentada de manera irrompible, es pormenorizada en 596 páginas que precisan lo contrario, no de forma radical, por supuesto, pero dejando en evidencia que "Chile no sólo enseña de valiosos acuerdos sino también de profundos errores" (Ffrench-Davis, 2018, p. 13).

Estudiante de pregrado en la Escuela de Sociología de la Universidad Católica Silva Henríquez, Santiago, Chile. Contacto: varevalo@miucsh.cl 
De manera concreta, lo que el autor pone en evidencia son logros y fracasos socioeconómicos, con una visión de crecimiento sostenido e incluyente, fundamentado éste en espacios para el desarrollo productivo del mundo laboral. Ello debido a que la finalidad del autor con sus investigaciones es la búsqueda activa y congruente de un crecimiento con equidad, abordando los fenómenos estudiados con "pragmatismo o realismo". Dichas contemplaciones no emergen sin explicación, sino que los lectores debemos tener en consideración que este ingeniero comercial, con formación en la Pontificia Universidad Católica de Chile, con posgrado en la Universidad de Chicago, fue fundador de la Corporación de Investigaciones Económicas para Latinoamérica (Cieplan), actual Corporación de Estudios para Latinoamérica, que contribuyó intelectualmente con el programa del primer gobierno de la Concertación y cuyo lema se basó en la idea de "crecimiento con equidad". Un dato interesante, a la hora de analizar el texto y la visión que tiene el autor de las diversas reformas.

El libro se encuentra estructurado con una introducción, que trata sobre el desarrollo económico chileno desde 1973, y se divide en siete apartados: 1) las estrategias económicas en perspectiva histórica, abarcando la estrecha relación y conciliación del contexto internacional con el nacional, destacando hitos históricos como la Gran Depresión, la gran crisis, la Segunda Guerra mundial y la trascendencia en la aplicación de diversos razonamientos económicos por parte de los gobiernos de dichos periodos; 2) la estrategia neoliberal de la dictadura (1973-1989), dividida en dos periodos y separada por la crisis financiera. El primero comprende entre 1973 a 1981, siendo un reflejo de una ortodoxia o neoliberalismo puro, en su forma más extrema. El segundo, desde 1982 hasta 1989, marcado por numerosas intervenciones heterodoxas; 3 ) las reformas significativas y un crecimiento excepcional de los primeros nueve años de retorno a la democracia; 4) retrocesos macroeconómicos pero avances en las políticas sociales, desde 1999 a 2007; 5) entre 2008 y 2013 el autor 
informa de vaivenes económicos, haciéndose presente un contagio recesivo, una recuperación y una desaceleración; 6) un nuevo ciclo, con rezagos de la dictadura, que se intentan palear con reformas "estructurales" y nuevos desafíos; para terminar 7) con una evolución desde la dictadura a la democracia: las reformas, contrareformas e incercias hasta 2017.

La primera parte del libro se titula "El experimento neoliberal y sus herencias, 1973-1989", constatando la liberalización de la economía, el proceso de crisis de la deuda externa, los problemas sociales que se experimentaron durante la dictadura, específicamente de desigualdad y pobreza, junto con el desarrollo económico apoyado en las exportaciones durante los setenta y ochenta.

La segunda parte del libro lleva como título "Los desafíos para el desarrollo en democracia", abordando el factor exportador y el crecimiento de los noventa, junto con las regulaciones de las entradas de capitales en el mismo periodo. En esta sección se deja en evidencia las fluctuaciones propias de la economía, como la recesión de 1999 a la recuperación del 2004-08, la crisis global del 2008-13, etc. Y, al igual que en el capítulo anterior, se constata la desigualdad y la pobreza pero, en este caso, desde los noventa.

El libro termina con recuentos, basados en un contraste entre la evolución de Chile respecto de lo ocurrido en América Latina y el mundo. Tres conclusiones generales: la equidad es imprescindible para el crecimiento sostenido y pasa por las PYMEs, la recuperación de una macroeconomía para el desarrollo y un creciente déficit de un espíritu innovador, productivo e incluyente. Además, plantea Ffrench-Davis siete desafíos concretos: recuperación de macroeconomía para un desarrollo sostenible, políticas de desarrollo productivo, dinamismo exportador intenso en mayor valor agregado, junto a reformas correctivas de la política cambiaria, una inversión productiva pública y privada, una reforma tributaria para la obtención de financiamiento y, por último, transformaciones estructurales centradas en un sistema económico, social, educacional, cultural, creciente e incluyente. 
Mirado en perspectiva, el trabajo desarrollado por Ricardo Ffrench-Davis resulta sumamente valioso, debido a que aborda una serie de temas con información, análisis y propuestas vigentes, tanto en lo académico e intelectual, como lo político y social, trascendiendo ideologías y profesiones. El recorrido histórico que abarca presenta una visión profunda y evolutiva de un pasado no tan lejano; evidencia un presente basado pero no petrificado en ello, plasmando turbulencias económicas y sociales paleadas por múltiples reformas; mostrándonos los procesos políticos que han convergido durante cincuenta años, permitiéndonos reflexionar sobre el actuar de los gobiernos en relación a cifras económicas y a la construcción de país y sociedad que se ha formado y priorizado.

La reedición de este libro da cuenta de lo actual y relevante de lo vertido, a 30 años del plebiscito para restaurar la democracia en Chile, por la trascendencia económica, política y social que dejó la dictadura, junto a las decisiones que se tomaron en transición y se cimentaron en los gobiernos venideros. Por lo que las temáticas abordadas siguen siendo parte del debate nacional, cuestionándose el aparato estatal, junto a sus representantes, el modelo económico y de desarrollo por parte de la ciudadanía, mediante constantes demandas y erosiones que tensionan la democracia chilena.

En este sentido, el libro cobra importancia para la sociología, porque esta disciplina se cimentó bajo una mirada económica de los padres fundadores de principios del siglo XX (Weber, Marx y Durkheim), por lo que tener análisis de la propia realidad, de manera profunda y evolutiva, es un gran aporte teórico-empírico para la comprensión de fenómenos sociales del país. La rama de la sociología económica se enriquece con las teorías económicas para la elaboración de mejores explicaciones sobre esta clase de hechos, por lo que unir y complementar estas dos disciplinas es esencial para la comprensión de los hechos sociales:

En lugar de oponerlas, como se hace tradicionalmente, es hora de comprender que sociología y economía constituyen en realidad, una sola y misma disciplina, que tie- 
ne por objeto el análisis de los hechos sociales, de los que las transacciones económicas, después de todo, no son más que un aspecto (Bourdieu, 2001, p. 26).

Dejando de lado la disciplina en la que se basó la mirada y enfoque del libro, existen otros componentes que la sociología puede rescatar para el análisis, en sus diversas ramas, como las políticas públicas implementadas en esos periodos, la construcción de sociedad que se gestó durante la transición, todo lo que respecta al neoliberalismo en sus múltples aristas, pudiendo analizarse en retrospectiva la perpetuación, modificación o eliminación de un modelo económico que transformó a Chile en lo que somos actualmente, etc.

Es, por tanto, un libro que nos incita constantemente a la reflexión de lo que fuimos e hicimos, lo que somos y lo que buscamos, entendiendo que las reformas instauradas y las venideras constituyen un componente esencial a la hora de conformar las pautas culturales de un país.

\section{Referencias}

Bourdieu, P. (2001). Las estructuras sociales de la economía. Buenos Aires: Ediciones Manantial.

Ffrench-Davis, R. (2018). Reformas económicas en Chile, 1973-2017. Santiago: Penguin Random House Grupo Editorial. 
